\title{
El COVID-19 y las 3 "P": Pandemia, Pediatría y su impacto en el País
}

\author{
COVID-19 and the 3 "P": Pandemic, Pediatrics and \\ impact in the Country
}

\author{
Juan Pablo Torres Torrettia , Miguel O’Ryan Gallardo ${ }^{\mathrm{b}}$
}
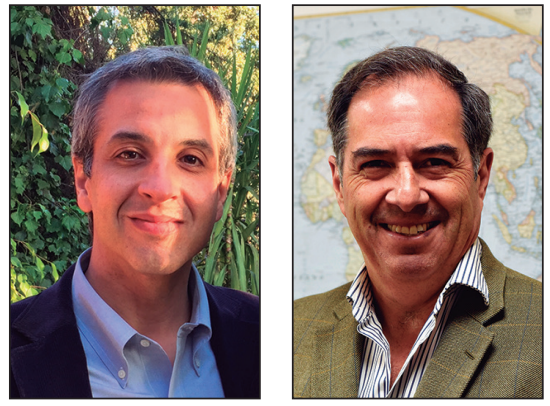

aDepartamento. de Pediatría y Cirugía Infantil Oriente. Director de Innovación. Facultad de Medicina, Universidad de Chile. Departamento de Pediatría, Clínica Las Condes. Chile.

bPrograma de Microbiología y Micología, Instituto de Ciencias Biomédicas ICBM, Facultad de Medicina, Universidad de Chile. Miembro del Consejo Asesor COVID-19, Ministerio de Salud de Chile. Chile.

El comienzo del año en curso trajo consigo la emergencia de un nuevo virus, el SARS-CoV-2, responsable de la enfermedad COVID-19, que se extendió desde China al resto de Asia, luego Europa y actualmente concentrándose activamente en la región de las Américas. Con cerca de 6 millones de casos reportados en todo el planeta ${ }^{1}$ y acercándonos a los 100.000 de ellos en nuestro país a fines de mayo ${ }^{2}$, estamos viviendo posiblemente los momentos más duros y complejos de la pandemia, causada por un virus para el cual no disponemos de tratamiento antiviral específico ni vacuna. Frente a esto, los países intentan "modular" en parte la evolución natural del nuevo coronavirus, con mayor o menor éxito, a través de medidas empíricas de aislamiento social, cierres de fronteras, colegios, comercio, cuarentenas extensas y/o dinámicas, que han venido a transformar de manera abrupta nuestros hábitos, formas de relacionarnos y generando un importante impacto sanitario, social, mental, político y económico tanto actual como venidero.

La pandemia del SARS-CoV-2 plantea varias interrogantes y desafíos en el ámbito de la pediatría. Primero, hemos aprendido que los niños tienden a tener cuadros clínicos más leves o asintomáticos y no superan el 3-6\% del total de casos reportados ${ }^{3,4}$. Ha ido emergiendo evidencia científica que apunta a que los niños no tienen un rol protagónico en la transmisión del virus, a diferencia de lo que sabemos para otros virus respiratorios como influenza. Estudios reportados desde Islandia, Holanda y Australiaa ${ }^{5,6,7}$ muestran resultados de menor frecuencia de infección en niños; en el estudio islandés, que realizó testeo en el $6 \%$ de la población del país, se observó un diferencia significativamente menor de positividad en niños menores de 10 años versus mayores de 10 años (6,7\% vs 13,7\%), mientras que estudios holandeses en curso apuntan a que los niños estarían generando poco contagio hacia sujetos adultos. Así mismo, recientemente se ha descrito que los niños menores de 10 años tienen una expresión significativamente más baja de la enzima convertidora de angiotensina 2 (ACE2), el receptor que el SARS-CoV-2 utiliza para su entrada a la célula, en comparación con sujetos mayores de 10 años, donde la expresión de ACE2 va aumentando paulatinamente con la edad ${ }^{8}$. Esta información podría ayudar a explicar en parte la menor frecuencia de infección observada en

Correspondencia: 
niños. Segundo, hemos aprendido que pueden emerger nuevas presentaciones clínicas, inhabituales pero que requieren alerta, como el síndrome inflamatorio multisistémico en niños, donde el cuadro clínico puede asemejar una enfermedad de Kawasaki y/o un shock tóxico ${ }^{9}$. Afortunadamente, se han reportado muy pocos casos y pareciera estar asociado a una condición más bien inmunológica post-infecciosa. Tercero, empezamos a ver con preocupación una caída en las coberturas de vacunas de los Programas de Inmunización de los países de nuestra región ${ }^{10}$. Ante esto, tenemos la responsabilidad de cautelar y promover la vacunación de los niños en época de pandemia, asegurando acceso, medidas de protección y continuidades de los programas, de manera de evitar la aparición de brotes de enfermedades prevenibles por vacunas (como sarampión o meningococo), así como del deterioro de enfermedades crónicas por un control de salud insuficiente. Por último, los efectos en el mediano y largo plazo de la pandemia nos pueden enfrentar a nuevos escenarios socioeconómicos, con aumento en las cifras de desempleo y pobreza que pueden generar cambios epidemiológicos en la niñez, con reemergencia de trastornos nutricionales, de salud mental y un potencial aumento de enfermedades infectocontagiosas respiratorias y digestivas.

Es clave estar a la altura de este desafío, combinando los aportes de los sectores clínico-asistenciales, las sociedades científicas, el mundo académico, social y político; en definitiva, donde todos los componentes de la sociedad, desde el cumplimiento de las medidas de prevención y mitigación por cada individuo, hasta el actuar colectivo, deberán estar alineados y centrados en las soluciones más que en la denuncia de problemas, para lograr el mejor resultado posible. Los países, incluyendo el nuestro, serán capaces de ir superando la situación actual, unos antes que otros, con mayor o menor grado de éxito (que podría definirse como quienes logren la menor tasa de mortalidad con el menor impacto social). Esto, en espera de una próxima vacuna para COVID-19,algunas de las cuales, en un desarrollo hiperacelerado sin precedentes, se encuentran actualmente en fase 2 a 3 .

Sin dudas, las vivencias asociadas a esta pandemia, única en nuestras vidas, deberán ser aprovechadas por toda la comunidad para reflexionar sobre las necesarias mejoras en diversos ámbitos de la vida nacional, desde lo sanitario a lo humano, pasando por lo político y social. El Chile post pandemia podrá ser un peor, o como esperamos, un mejor país, lo que dependerá de cada uno de nosotros.

\section{Conflictos de interés}

Los autores declaran no tener conflictos de interés.

\section{Referencias}

1. World Health Organization (WHO) COVID-19 Situation Report 127, May 26th 2020. Acceso a través de https://www.who.int/docs/defaultsource/coronaviruse/situationreports/20200526-covid-19-sitrep-127. pdf?sfvrsn=7b6655ab_8.

2. Reporte diario, 27 de mayo 2020. Plan de acción del COVID-19, Ministerio de Salud, Chile. Acceso a través de https://cdn.digital.gob.cl/public_files/ Campa\%C3\%Blas/Corona-Virus/ Reportes/27.05.2020_Reporte_Covid19. pdf.

3. The Novel Coronavirus Pneumonia Emergency Response Epidemiology Team. The Epidemiological Characteristics of an Outbreak of 2019 Novel Coronavirus
Diseases (COVID-19) - China, 2020[J]. China CDC Weekly, 2020, 2(8): 113-122. doi: $10.46234 / \mathrm{ccdcw} 2020.032$.

4. World Health Organization.

Coronavirus disease (COVID-19)

Situation Report-115. Acceso a

través de https://www.who.int/docs/ default-source/coronaviruse/situationreports/20200514-covid-19-sitrep-115. pdf?sfvrsn=3fce8d3c_4.

5. Gudbjartsson DF, Helgason A, Jonsson $\mathrm{H}$, et al. Spread of SARS-CoV-2 in the Icelandic Population. N Engl J Med 2020.

6. Children and COVID-19. National Institute for Public health and Environment, Ministry of Healt, Welfare and Sport, The Netherlands. Acceso a traves de https://www.rivm.nl/en/novelcoronavirus-covid-19/children-andcovid-19.
7. COVID-19 in schools - the experience in New South Wales. Prepared by the National Centre for Immunisation Research and Surveillance (NCIRS), Australia, 26 April 2020.

8. Bunyavanich S, Do A, Vicencio A. Nasal Gene Expression of AngiotensinConverting Enzyme 2 in Children and Adults. JAMA 2020.

9. Belhadjer Z, Meot M, Bajolle F, et al. Acute heart failure in multisystem inflammatory syndrome in children (MIS-C) in the context of global SARSCoV-2 pandemic. Circulation 2020.

10. Santoli JM, Lindley MC, DeSilva MB, et al. Effects of the COVID-19 Pandemic on Routine Pediatric Vaccine Ordering and Administration - United States, 2020. MMWR Morb Mortal Wkly Rep 2020;69:591-3. 